10

\title{
Корреляция между теплофизическими и акустическими свойствами В нефтях
}

\author{
(C) В.Г. Кучеров, ${ }^{1,2}$ С.Г. Серебряков, ${ }^{1}$ А.И. Черноуцан ${ }^{1}$ \\ ${ }^{1}$ Российский государственный университет нефти и газа (научно-исследовательский университет) им. И.М. Губкина, \\ 119991 Москва, Россия \\ ${ }^{2}$ KTH Royal Institute of Technology Lindstadtsvagen 30, \\ SE-100 44 Stockholm, Sweden \\ e-mail: vladimir@flotten.se
}

Поступило в Редакцию 22 июня 2018 г.

В окончательной редакции 11 июня 2019 г.

Принято к публикации 25 июля 2019 г.

\begin{abstract}
Представлены результаты измерения теплофизических и акустических свойств четырех различных природных нефтей в диапазоне температур 293-353 K при атмосферном давлении. Показано наличие корреляционной связи между теплофизическими и акустическими свойствами в нефтях. Наличие корреляционной связи указывает на возможность применения представлений о переносе теплоты в сложных углеводородных системах посредством гиперакустических звуковых движений с учетом их поглощения и рассеяния на флуктуациях плотности.
\end{abstract}

Ключевые слова: нефти, теплофизические и акустические свойства, температура.

DOI: $10.21883 / J T F .2020 .01 .48674 .247-18$

\section{Введение}

В настоящее время не существует удовлетворительной теории теплопроводности жидкостей, что связано с отсутствием последовательной теории жидкого состояния. Большое количество теоретических и полуэмпирических зависимостей, предлагаемых различными авторами, лишь подтверждает этот факт. Подробный анализ существующих теорий теплопроводности жидкостей можно найти в работах [1-3]. Ниже приводится краткий обзор основных существующих подходов.

\section{Статистический подход}

В работе [4] коэффициент теплопроводности вычисляется на основе модифицированного интеграла столкновений Больцмана. Этот подход дает удовлетворительные результаты только для плотных газов.

В работах [5] сделана попытка получить кинетическое уравнение, позволяющее определить неравновесные функции распределения. Движение молекул рассматривается как броуновское движение, функции распределения типа Фоккера-Планка получаются из модифицированного уравнения Луивилля. Перенос энергии происходит как за счет движения молекул, так и за счет попарных соударений. При этом первый вклад оказывается пренебрежимо малым.

В ряде работ [6-8] использовалась более простая решетчатая модель жидкости, в которой исключалось объемное движение молекул. Каждая молекула совершает колебания в своей ячейке, передача энергии происходит при соударениями с молекулами из соседних ячеек. Коэффициент теплопроводнсти выражается через частоту колебаний.

Попытки применения к органическим жидкостям общей схемы вычисления явлений переноса путем получения временных корреляционных функций столкнулись с непреодолимыми трудностями. Построение последовательной статистической теории теплопроводности жидкости находится в зачаточном состоянии.

Недостатки перечисленных подходов заключаются в том, что они не являются чисто статистическими, а опираются на слабо обоснованные представления модельного характера. Полученные результаты содержат неопределенные коэффициенты и носят полуэмпирический характер. Но главное - они не используют представление о коллективном характере движения молекул жидкости.

\section{Эмпирические формулы}

В последние годы были разработаны математические методы обработки больших массивов данных, позволяющие получать оптимальные эмпирические формулы, содержащие небольшое число подгоночных параметров. Эти формулы имеют большое практическое значение и активно используются [9]. Самой удачной можно считать формулу Латини [10] для зависимости теплопроводности органических жидкостей от приведенной температуры:

$$
\lambda=A \cdot 1.951\left[\frac{(\tau-0.1)^{0.3}}{(1.1-\tau)^{1 / 6}}\right],
$$

где $\tau=T / T_{\text {cr }}$ - приведенная температура, а эмпирический коэффициент $A$ подбирается для каждого семейства 
Таблица 1. Характеристики исследованных нефтей

\begin{tabular}{|c|c|c|c|c|}
\hline & Образец 1 & Образец 2 & Образец 3 & Образец 4 \\
\hline $\begin{array}{l}\text { Плотность при } 293 \mathrm{~K}, \mathrm{~kg} / \mathrm{m}^{3} \\
\text { Молекулярная масса } \\
\text { Температура начала кипения, К } \\
\text { Вязкость при } 323 \mathrm{~K}, \mathrm{~mm}^{2} / \mathrm{s}\end{array}$ & $\begin{array}{l}831 \\
225 \\
308 \\
10.5\end{array}$ & $\begin{array}{r}861 \\
265 \\
343 \\
9.8\end{array}$ & $\begin{array}{l}911 \\
280 \\
351 \\
127\end{array}$ & $\begin{array}{r}837 \\
265 \\
353 \\
5.7\end{array}$ \\
\hline \multicolumn{5}{|c|}{ Содержание, \% } \\
\hline $\begin{array}{l}\text { силикагелевых смол } \\
\text { асфальтенов } \\
\text { парафинов } \\
\text { воды }\end{array}$ & $\begin{array}{l}6.3 \\
1.0 \\
8.1 \\
-\end{array}$ & $\begin{array}{c}12 \\
2.8 \\
4.5 \\
-\end{array}$ & $\begin{array}{l}- \\
6.6 \\
3.1 \\
-\end{array}$ & $\begin{array}{r}4.2 \\
0.8 \\
13.2 \\
-\end{array}$ \\
\hline \multicolumn{5}{|c|}{ Фракционный состав, vol.\% } \\
\hline $\begin{array}{l}\text { до } 100^{\circ} \mathrm{C} \\
\text { до } 200^{\circ} \mathrm{C} \\
\text { до } 300^{\circ} \mathrm{C}\end{array}$ & $\begin{array}{l}10 \\
18 \\
20\end{array}$ & $\begin{array}{r}6 \\
22 \\
16\end{array}$ & $\begin{array}{r}2 \\
13 \\
18\end{array}$ & $\begin{array}{l}1.6 \\
23 \\
20\end{array}$ \\
\hline
\end{tabular}

Примечание: образец 1 - нефть Сосновского месторождения (Белоруссия), образец 2 - нефть Каратюбинского месторождения (Казахстан), образец 3 - нефть Зюзеевского месторождения (Россия), образец 4 - нефть Харьягинского месторождения (Россия).

жидкостей. Несмотря на практическую важность, эти уравнения ничего не дают для понимания природы теплопроводности в жидкостях.

\section{Фононный механизм теплопроводности}

В этом подходе, наиболее последовательно учитывающем коллективный характер движений в жидкости, рассматривается перенос энергии гиперакустическими колебаниями (фононами) в духе модели Дебая. Для коэффициента теплопроводности получается выражение [11]:

$$
\lambda=\frac{4 \pi}{3} \int_{0}^{\omega_{\max }} \frac{1}{\alpha} \cdot \frac{\partial \varepsilon}{\partial T} d \omega,
$$

где $\varepsilon-$ интенсивность равновесного излучения гиперзвука в среде, $\alpha-$ коэффициент поглощения волн. Это уравнение может быть приведено к виду, используемому в кинетической теории газов:

$$
\lambda=\frac{1}{3} c_{v} \rho u l,
$$

где $u$ - скорость звука, $l-$ средняя длина свободного пробега фононов, равная длине затухания гиперакустических волн (величина, обратная $\alpha$ ).

Первая работа в рамках этого подхода была выполнена Н.П. Пашским в 1914г. [12]. Затем этот подход использовал Бриджман [13], принявший $l$ равной среднему расстоянию между молекулами. В работах [14-17] использовалось представление о „свободном объеме“ и учитывались внутренние степени свободы. В работе Широкова [18] после исключения $l$ из уравнений для вязкости и теплопроводности получалась формула, связывающая их друг с другом. В перечисленных работах получалось только качественное согласие для зависимости $\lambda$ от $T$, но количественное расхождение с экспериментом было весима значительным. Как правило, предсказанные значения теплопроводности существенно (иногда больше чем на порядок) превышали результаты экспериментов.

Существенный прогресс в теоретическом описании теплопроводности в рамках представлений о переносе энергии гиперакустическими колебаниями был достигнут Филипповым [2]. Ему удалось получить хорошее количественное согласие с экспериментом для большого числа органических жидкостей. Прогресс был достигнут за счет включения в расчет ослабления дебаевских волн наряду с различными механизмами их поглощения (диссипация за счет действия вязких сил и за счет теплопроводности) еще и процесса рассеяния этих волн на флуктуациях плотности среды (т.е. на тех же гиперакустических колебаниях). Он пришел к выводу, что безразмерная функция

$$
\psi=\psi(\tau)=\frac{\lambda}{u\left(c_{p} \rho\right)^{2 / 3} k^{1 / 3}},
$$

где $k$ - постоянная Больцмана должна быть одинаковой для различных веществ при одинаковых приведенных температурах $\tau=T / T_{\text {cr. }}$ Л.П. Филиппов проверил это утверждение для 28 неассоциированных жидкостей при разных температурах и получил согласие с погрешностью $4 \%$.

В настоящей работе мы представляем результаты измерения теплофизических и акустических свойств четырех различных природных нефтей при атмосферном давлении и различных температурах. Обработка результатов показала,что все полученные данные ложатся на ту же самую линию $\psi(\tau)$, которая была получена Филипповым, подтверждая высокую универсальность 
Таблица 2. Экспериментальные значения теплофизических свойств и скорости звука для исследованных нефтей при различных температурах

\begin{tabular}{l|c|c|c|c|c|c|c}
\hline Образец нефти & $T, \mathrm{~K}$ & $\rho, \mathrm{kg} / \mathrm{m}^{3}$ & $T_{\mathrm{pcr}}, \mathrm{K}$ & $\tau$ & $\lambda, \mathrm{W} /(\mathrm{m} \cdot \mathrm{K})$ & $c_{p}, \mathrm{~kJ} /(\mathrm{kg} \cdot \mathrm{K})$ & $U, \mathrm{~m} / \mathrm{s}$ \\
\hline Сосновская & 293 & 830.9 & & 0.419 & 0.122 & 1.925 & 1210 \\
& 313 & 816.1 & 670 & 0.447 & 0.117 & 2.072 & 1032 \\
Каратюбинская & 333 & 801.4 & & 0.476 & 0.108 & 2.182 & 938 \\
& 393 & 861 & & 0.385 & 0.127 & 1.915 & 1346 \\
Зюзеевская & 333 & 847.3 & 762 & 0.411 & 0.121 & 2.100 & 1185 \\
& 293 & 833.5 & & 0.437 & 0.115 & 2.156 & 1057 \\
Харьягинская & 313 & 898.5 & 869 & 0.337 & 0.124 & 1.836 & 1420 \\
& 333 & 886.1 & & 0.383 & 0.119 & 1.877 & 1331 \\
& 313 & 837.2 & & 0.411 & 0.128 & 1.866 & 1246 \\
& 333 & 822.7 & 714 & 0.439 & 0.122 & 2.015 & 1134 \\
\end{tabular}

рассмотрения теплопроводности через распространение гидроакустических волн.

\section{Описание исследованных образцов}

В качестве объектов исследования в настоящей работе были выбраны 4 образца дегазированных обезвоженных нефтей, существенно различающихся как по групповому составу, так и по основным физико-химическим свойствам. Относительная плотность определялась пикнометрическим методом по ГОСТ 3900-47, молекулярная масса определялась криоскопическим методом в бензоле с погрешностью $\pm 4 \%$, кинематическая вязкость при $323 \mathrm{~K}$ - капиллярным вискозиметром с погрешностью $\pm 0.1 \%$. Общее количество парафинов определялось методом низкотемпературной депарафинизации (ГОСТ 11851-85), содержания воды, смол и асфальтенов - общепринятыми методами исследования. Характеристики исследованных нефтей приведены в табл. 1.

\section{Проведение экспериментов}

В экспериментах измерялись коэффициент теплопроводности, удельная массовая теплоемкость и скорость распространения ультразвуковых волн в описанных выше четырех образцах нефтей при тепературах 293, 333 и $353 \mathrm{~K}$ при атмосферном давлении. Измерения теплопроводности $\lambda$ и удельной массовой теплоемкости $c_{p}$ проводились на установке, работающей по методу коаксиальных цилиндров. Подробные описания метода измерения, конструкции прибора, расчета погрешности измерений и методики проведения экспериментов изложены в [19]. Максимальная относительная погрешность определения коэффициентов теплопроводности для описанного выше метода не превышала $25 \%$, удельной массовой теплоемкости - 4.7\% [19]. Измерение скорости распространения ультразвуковых волн $u$ проводилось на стандартном приборе УИП-8Ф, позволяющем проводить измерения в температурном диапазоне 293-333 К с погрешностью, не превышающей 1\%. Результаты экспериментов представлены в табл. 2.

Под приведенной температурой $\tau$ понималось отношение текущей температуры $T$ к псевдокритической $T_{\text {pcr. }}$. В настоящее время среди различных подходов при определении критической (псевдокритической) температуры смесей жидкостей получил развитие так называемый „одножидкостной“ подход, когда смесь рассматривается как некоторое чистое вещество, обладающее собственными индивидуальными критическими характеристиками („псевдокритические“ параметры). Именно этот подход был использован в настоящей работе при рассмотрении сложных углеводородных систем.

Псевдокритическая температура рассчитывалась по выражению, полученному Филипповым в работе [20]:

$$
T_{p_{\mathrm{cr}}}=0.493\left(\frac{293 \cdot \rho_{T}-T \cdot \rho_{293}}{\rho_{T}-\rho_{293}}\right),
$$

где $\rho_{293}$ и $\rho_{T}-$ плотность нефти при температурах 293 и $333 \mathrm{~K}$ - определялась экспериментально стандартным пикнометрическим методом.

\section{Обсуждение результатов}

Используя подход Л.П. Филиппова о переносе теплоты в жидкостях посредством гиперакустических звуковых волн с учетом их поглощения и рассеивания на флуктуациях плотности, можно записать следующую зависимость, связывающую теплофизические и акустические свойства органических жидкостей:

$$
\lambda=\psi(\tau) \cdot u\left(c_{p} \rho\right)^{2 / 3} k^{1 / 3},
$$

где $\psi$ - безразмерная функция,определяемая из экспериментальных данных; $k-$ постоянная Больцмана $1.38 \cdot 10^{-23} \mathrm{~J} / \mathrm{K}$.

Как отмечено в работе [2], безразмерная функция $\psi(\tau)$ должна быть одинаковой для различных органических 


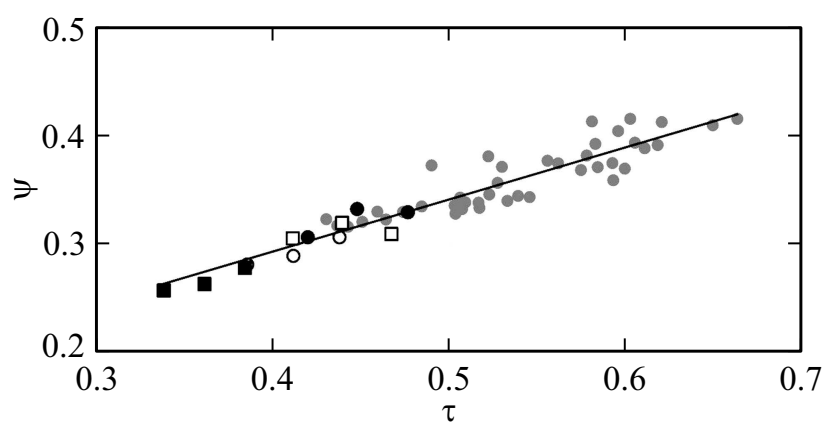

Зависимость безразмерной функции $\psi$ от приведенной температуры $\tau$ : данные для 28 неассоциированных жидкостей [20] (серые кружки), образец 1 (черные кружки), образец 2 (белые кружки), образец 3 (черные квадраты), образец 4 (белые квадраты).

жидкостей. Как видно из рисунка, это утверждение справедливо и для исследованных нефтей. Для 54 экспериментальных точек, включая 12 точек, полученных для исследованных нефтей, среднее отклонение от расчетных данных не превышает 4\%.

Обработка экспериментальных данных по методу наименьших квадратов (рис. 1) позволила получить следующий вид безразмерной функции $\psi$ :

$$
\psi=0.064+0.54 \tau
$$

где приведенная температура $\tau$ расчитывалась как отношение текущей температуры $T$ к псевдокритической. Псевдокритическая температура рассчитывалась по выражению (5).

\section{Заключение}

Полученные экспериментальные данные позволяют сделать вывод о наличии корреляционной связи между теплофизическими и акустическими свойствами в нефтях.

Наличие корреляционной связи указывает на возможность применения представлений о переносе теплоты в сложных углеводородных системах посредством гиперакустических звуковых движений с учетом их поглощения и рассеяния на флуктуациях плотности.

\section{Финансирование работы}

Работа осуществлялась при финансовой поддержки шведской фирмы Flotten AB.

\section{Конфликт интересов}

Авторы заявляют, что у них нет конфликта интересов.

\section{Список литературы}

[1] Миснар A. Теплопроводность твердых тел, жидкостей, газов и их композиций. М.: Мир, 1968. 464 с.

[2] Филиппов Л.П. Исследование теплопроводности жидкостей. М.: МГУ, 1970. 240 с.

[3] Kutcherov V.G., Håkansson B., Ross R.G. et al. // J. Appl. Phys. 1992. Vol. 71. P. 1732-1736.

[4] Enskog D. // Kungl. Svenska Vetenskap Akademiens Handlingar. 1922. Vol. 63. N 4. P.5-44.

[5] Rice S.A., Kirkwood J.G., Ross J. et al. // J. Chem. Phys. Vol. 31. P. 575-583.

[6] Osida J. // Proc. Phys.-Math. Soc. Jpn. 1939. Vol. 21. N 6. P. 353-367.

[7] Horroks J.K., McLaughlin E. // Proc. Roy. Soc. (London). 1963. A273. P. 259-274.

[8] McLaughlin E. // Chem. Rev. 1964. Vol. 64. P. 390-428.

[9] Poling B.E., Prausnitz J.M., O'Connell J.P. The properties of gases and liquids, 5th ed. NY:: McGraw-Hil, 2001. 768 p.

[10] Latini G., Baroncini C. // High. Temp. High. Press. 1982. Vol. 15. P. 407-411.

[11] Brillouin L. // Compt. Rend. 1914. Vol. 159. P. 27-30.

[12] Пашский Н.П. // ЖРФХО. 1915. Т. 48. С. 276-282.

[13] Bridgman P.W. // Proc. Am. Acad. Arts Sci. 1923. Vol. 59. P. $141-169$.

[14] Kincaid J.E., Eyring H. // J. Chem. Phys. 1938. Vol. 6. P. 620 629.

[15] Боровик Е.В. // ЖЭТФ. 1948. Т. 8. Вып. 1. С. 48-52.

[16] Kardos A. // Z. Ges. Kälte-Ind. 1934. Vol. 41. P. 1-6, 29-35.

[17] Sakiadis B.C., Coates J. // Am. Inst. Chem. Eng. J. 1955. Vol. 1. N 3. P. 275-288.

[18] Широков М.Ф. В сб.: Вязкость жидкостей и коллоидных растворов. АН СССР, М. 1944. С. 35.

[19] Кучеров В.Г. Дисс. канд. техн. наук. М: МИНХ и ГП, 1987. $141 \mathrm{c}$.

[20] Филиппов Л.П. Закон соответственных состояний. М.: МГУ, 1983. 168 с. 